\title{
21 criaga
}

\section{A Ética NA REPRESENTAÇÃo dO HORROR EM LA DOUleur, de Marguerite Duras}

\author{
Laura Degaspare Monte Mascaro ${ }^{1}$
}

\begin{abstract}
REsumo: Partindo da constatação de que os horrores dos campos de concentração e extermínio tornaram imperativo que se questionasse sobre como a literatura de teor testemunhal e a literatura em geral apresentavam o passado, assim como a contribuição dessa representação para o futuro e o mundo compartilhado, o presente artigo buscará investigar a obra La Douleur (1985) de Marguerite Duras sob a perspectiva da ética da representação do horror e da dor. PalaVRas-Chave: literatura de testemunho; ética; horror; Marguerite Duras
\end{abstract}

\section{Ethics in the representatation of horror in Marguerite Duras' La Douleur}

AbStRACT: From the perception that the horrors of the concentration and extermination camps forced us to question how literature in general and testimonial literature in specific portrays the past, so as their contribution to the future and to the shared world, the present article intends to investigate Marguerite Duras' La Douleur (1985) from the perspective of the ethics of the representation of horror and pain.

KEYwORDS: testimonial literature; ethics; horror; Marguerite Duras

\section{Introdução}

A literatura de testemunho posterior a Auschwitz levanta a questão de uma ética da representação do passado traumático, o que implica pensar nas aporias em torno das quais se movimentam a tarefa da memória e da escritura quando não é possível lembrar ou traduzir totalmente o passado. O compromisso com o real na literatura de testemunho exige, assim, a reavaliação do papel da literatura. A relação do autor com o passado ao qual ele tenta dar forma tem o caráter de um compromisso ético, e não é diferente na obra La Douleur (1985) de Marguerite Duras, que será objeto de uma análise pelo prisma axiológico no presente artigo, em especial no que tange seu modo de representação do horror.

O texto La Douleur ocupa um lugar à parte na obra de Marguerite Duras. Trata-se de uma obra de teor testemunhal, que teria vindo a público quase que acidentalmente quando Duras encontrou, nos armários azuis de sua casa em Neauphle-le-Château, os cadernos que contêm as primeiras versões de alguns textos redigidos por ela na Segunda Guerra Mundial, durante a ocupação nazista da França e logo após a liberação. Consiste em uma coletânea de seis textos que tratam principalmente da experiência da autora durante aquele período, conjugando drama histórico e sofrimento pessoal.

Após a Shoah, é retomada a questão proposta por Sócrates acerca da conveniência e inconveniência da escritura - "enquanto saber se, justamente, é decente ou indecente escrever, em quais condições é bom que isso se faça e em quais isso seria inconveniente" (DERRIDA, 2005, p. 18) -, questionando-se a possibilidade da literatura pós-Auschwitz. Os extermínios perpetrados pelo totalitarismo nazista teriam tocado o homem e Deus em seu âmago, motivo pelo qual todas as interrogações contemporâneas têm como fundo a Shoah (BORNAND, 2004, p. 14). Conforme Seligmann-Silva (2003, p. 73), ao tratar de Friedländer, "quem fala em ética fala em limite, fala em fronteiras a serem respeitadas - não por uma deficiência técnica da parte do historiador, mas sim devido a uma reflexão sobre o significado da 'representação total do passado nazista'”. Esse

1 Graduada em Direito (2007), Mestre pelo departamento de Filosofia e Teoria Geral do Direito da Faculdade de Direito da USP (2011) e Doutora em Literatura Francesa na Faculdade de Filosofia, Letras e Ciências Humanas da USP (2017). laura.mascaro@usp.br 


\section{1}

compromisso com a ética é ainda mais relevante se considerarmos a dimensão performativa da escritura, notadamente na literatura com teor testemunhal, em que "dans la parole, justement, un monde apparaît, conséquence de ce qu'on dit” (BOURDIL, 1987, p. 20).

Uma das questões pertinentes a essa temática é a relação da mentira com a ficção, que seria regida por um contrato de veridiç̧ão, ou, no caso da literatura de caráter testemunhal, pelo contrat de vérité. A escritura durasiana contém diversas camadas de significado que extrapolam a primeira dimensão de referencialidade a fatos passados, sendo muitas vezes utilizada como dissimulação. $O$ critério do falso e do verdadeiro enquanto fidelidade a uma origem não pode ser adotado de forma incontestável no julgamento dessa escritura que "diz a verdade" por meio da ilusão e do simulacro: "[...] elle introduit à l'intérieur du texte une structure de duplicité qui ne se laisse plus réapproprier dans une problématique de la vérité ou du mensonge ni maîtrises par elle" (KOFMAN, 1973, p. 178, apud BAJOMÉE, 1989, p. 164).

Desse modo, mesmo quando Duras confere a seus escritos a aparência de relatos factuais, fiéis aos acontecimentos, é preciso buscar o significado em uma segunda camada, o que não significa necessariamente que a escritora esteja mentindo, apenas que o verdadeiro e o falso não são critérios adequados para se julgar a "verdade", ou melhor, o sentido em seus textos. Aos poucos, em sua obra, a autora abandona até mesmo a ilusão de realidade, recusando-se a aderir a uma verossimilhança codificada, o que fica claro nos dois últimos textos do livro.

Essa experimentação de formas, que coloca em xeque a representação da metafísica clássica, extrapola, segundo Bajomée, o debate estético e a busca técnica, narratológica. Tentando formular uma resposta ao irrepresentável, Duras aproxima-se cada vez mais dele, inserindo-se em um debate ético - o de como representar o irrepresentável e o que não se dá naturalmente à representação -, que necessariamente possui um cunho estético. É possível notar o exercício das formas que testam os limites, assim como as estratégias, ao longo do livro, para abordar o que não seria adequado à representação, indo da forma mais obscena àquela que apenas toca o contorno das coisas, acolhendo em si a perda e a impossibilidade.

\section{O obsceno em La Douleur}

A literalidade das representações do Holocausto é motivo de preocupação para Maria Rita Kehl (2000) e Márcio Seligmann-Silva (2000). Segundo este, uma das características da recordação da cena traumática seria, na maioria dos casos, sua literalidade. A Shoah resistiria ao modo de representação metafórico porque sua recordação seria extremamente acríbica. A partir dessa constatação, Kehl coloca a seguinte questão: se o mal é representável, como falar dele sem produzir um efeito de gozo? Isso porque a pretensão de dizer tudo, de alcançar a coisa em si, poderia ser vista como uma tentativa de promover o gozo no abjeto. À luz dessa preocupação, iremos analisar a representação do horror em La Douleur, considerando que a própria Duras questionase a respeito da possibilidade de contar a "concomitance de sa propre vie et de cette horreur" (LAMY; ROY, 1981, p. 27).

A princípio, nos questionamos sobre a adequação do emprego da palavra "literalidade" em nossa análise. Na sua definição específica como "característica do que está inteiro, completo" (HOUAISS, 2003), seu sentido se aproxima ao da existência de uma linguagem que se confundiria ela própria com a realidade do evento, que seria representado em sua totalidade, o que, se 


\section{1}

considerarmos a realidade em sua acepção negativa - como aquilo que escapa à representação -, não pode, em última análise, se realizar.

Optamos, então, por adotar o conceito de "obscenidade" para tratar da ética da representação nos textos de Duras, não só porque discutiremos uma forma de representação - que por definição não pode ser total, nem tem essa pretensão -, mas também por acreditarmos que, se de algum modo o pensamento incidiu na reescritura dos textos quarenta anos após as primeiras versões, houve um julgamento ético e estético na forma de representar o vivido, convertendo-o em experiência. Esse julgamento determinou o que poderia aparecer em cena e o que permaneceria oculto, visto que nem sempre o que fica de fora num texto é o indizível, o irrepresentável, mas frequentemente é aquilo que está para além do ponto onde o escritor escolheu recuar (KEHL, 2000, p. 145), justamente por considerar o obsceno. O fato é que o debate ético sempre considera uma linha - em constante redefinição - que determina o que deve permanecer fora de cena, enquanto essa linha, na literalidade, aparentemente não é colocada em questão. Muitas vezes, a fronteira é ultrapassada precisamente porque a natureza daquilo que se pretende representar é a de não pertencer ao mundo das aparências, quando ocorreria então o obsceno.

Embora as diversas reescrituras do texto "La douleur" tenham buscado suavizar seu aspecto obsceno, acreditamos que ele ainda está presente. Refletindo a respeito de um dos sentidos originais da palavra obsceno, relacionado ao teatro - o daquilo que deve ficar "fora de cena" -, percebemos que se aproxima da noção formulada por Arendt (1992, p. 57) de "aparência inautêntica", que caracteriza aquilo que não estaria destinado ao mundo das aparências e que, caso seja forçado a se mostrar, seria de certo modo ou incompreensível ou repulsivo. Assim, há no texto de Duras dois elementos que só apareceriam de modo inautêntico, e cujo aparecimento incorre, portanto, na obscenidade: o interior do corpo e as emoções.

Remetendo novamente ao título da obra, que fornece uma chave de interpretação importante, encontramos referências à dor em diversos escritos de Duras, dentre o quais Appendices à Hiroshima: "Donner un signe extérieur de sa douleur serait dégrader cette douleur. [...] La douleur a son obscénité" (DURAS, 1972, p. 133). Fica claro que a dor não pertence ao mundo exterior, ao mundo das aparências, à cena: "L'évocation de la douleur abolit la frontière entre dedans et dehors, entre corps et le monde, entre le sujet et l'autre" (LOIGNON, 2003, p. 268). Isso é interessante porque se a dor, ao vir à tona, necessariamente perturba as fronteiras, também perturbaria o próprio critério do obsceno, que depende justamente do estabelecimento de uma linha que não deve ser ultrapassada, um critério não apenas estético, mas também ético.

A dor é uma espécie de crueldade que não é "sangrenta ou sanguinária, visível e exterior" (DERRIDA; ROUDINESCO, 2004, p. 170). No entanto, apenas quando torna-se exterior é que essa dor passa a fazer parte do mundo, que seu segredo é revelado como um sentido em um testemunho: "Et c'est cet être hors de soi, ce cri là où il déborde la parole de sagesse qu'un sujet ou qu'un moi entend contrôler, c'est cet être-hors-de-soi qui témoigne [...]”. (DERRIDA, 1992, fl. 6).

Devemos destacar, contudo, que a maneira como Duras faz emergir a dor pela escritura varia nos diversos textos que compõem a obra. A impressão é de que nos primeiros textos Duras aborda o horror de maneira direta, à flor da pele, enquanto que nos dois últimos, aqueles que ela aponta como inventados, a guerra e o horror da Shoah aparecem somente como pano de fundo, assim como a bomba em Hiroshima mon amour ${ }^{2}$. Nestes Duras se esquiva, circunda, desvia, como se das coisas só devesse subsistir a vaga sombra, o que acompanha a mudança estilística 


\section{1}

em seu trabalho literário e cinematográfico ao longo do tempo, até porque os últimos textos seriam mais recentes: "les descriptions très minutieuses des premiers romans font place à quelques évocations très brèves [...] destinées à créer un climat, évocations qui rejoindront une forme de maigreur, de vague, d'abstraction" (BAJOMÉE, 1989, p. 138-139).

Nos textos que derivam dos Cahiers des armoires bleues, que compreendem originalmente "La douleur", "Albert des Capitales" e "Ter le milicien", a experiência traumática é revivenciada pela escritura, presentificada e colocada diante de nossos olhos, especialmente em "La douleur". As emoções, no diário, aparecem de forma menos elaborada e conservam certos traços da desordem característica dos esboços: "Je me suis trouvée devant un désordre phénoménal de la pensée et du sentiment" (DURAS, 1985, p. 12). A forma desordenada é característica das afecções da alma:

[...] em que surgem nossas paixões, sentimentos e emoções, é um torvelinho de acontecimentos mais ou menos caóticos que não encenamos ativamente, mas que sofremos (pathein) e que, nos casos de grande intensidade, pode nos dominar, como a dor ou o prazer; sua invisibilidade assemelha-se à dos órgãos internos, cujo funcionamento ou não funcionamento também percebemos sem controlar (ARENDT, 1992, p. 57; grifos nossos).

Nesse texto, a alma se permite ver no estado mais puro, expresso da melhor maneira pelo próprio corpo, pelo olhar, pelo gesto, pelo som inarticulado, visto que a linguagem da alma em seu estado meramente expressivo, anterior à sua transformação e transfiguração pelo pensamento, não é metafórica (ARENDT, 1992, p. 26-27), assim como aquela pela qual se expressa o trauma. Em "La douleur", Duras coloca o corpo a serviço da expressão da alma - "On ne peut pas écrire sans la force du corps" (DURAS, 1993, p. 29) - em duas dimensões distintas: a formal e a do conteúdo da narrativa.

Para Derrida - a partir de suas reflexões acerca da Comissão de Verdade e Reconciliação da África do Sul - um aspecto importante do testemunho seria a presença física do corpo da vítima ou da testemunha. De acordo com o filósofo, "a cena do testemunho e da verdade, da revelação da verdade, encena o corpo da testemunha" (DERRIDA, 2005, p. 80). Partindo dessa observação, ao nos perguntamos como esse aspecto corporal pode ser observado na literatura de teor testemunhal, concluímos que o único corpo presente para o leitor, no texto escrito, é o corpo do próprio texto, que aqui também se desdobra em dois aspectos: o aspecto formal da narrativa, o corpo do texto, e o aspecto material do manuscrito, o arquivo, o rastro (trace) da escritura.

Santo Agostinho denuncia o equívoco hermenêutico que consistiria em privilegiar a letra em vez do espírito, considerando que a escrita seria equivalente ao corpo que aprisiona o espírito ou a alma, defendendo, portanto, uma leitura espiritual do texto em oposição à leitura carnal ou física. Fica claro que a leitura "carnal" seria aquela incapaz de alcançar além da primeira camada de significação literal, que não é a leitura que pretendemos realizar. Por outro lado, para Agostinho (2002), o corpo deve ser respeitado e a escritura deve ser preservada como o ponto de partida para a interpretação espiritual. Considerando que em um texto de caráter testemunhal seu corpo seria de extrema importância, visto que pode transparecer mais diretamente as afeç̧ões da alma que ele carrega consigo, devemos ir ainda mais longe e não apenas tomá-lo como ponto 


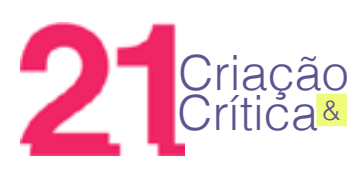

de partida, mas como componente fundamental da interpretação. No entanto, devemos ressaltar as limitações inerentes a este ponto da análise: a alma possui a mesma dificuldade dos nossos órgãos internos para se tornar parte do mundo das aparências e, ao pretendermos analisar não a forma como estes foram transpostos para o mundo externo pelo pensamento e pela linguagem metafórica, mas o transbordamento da alma para o plano corporal, nem sempre seu significado ficará claro, tornando a interpretação extremamente difícil.

Desse modo, em "La douleur", percebemos a expressão mais direta da alma no corpo do texto, de modo "sec et factuel [...], dépouillé de toute afféterie" (BOGAERT, 2014, p. 1342). A própria Duras, a posteriori, fala das características dessa linguagem que traz a dor em seu aspecto mais bruto - "la pauvreté du langage que la décrit" (DURAS, 2014j, p. 788). O relato de Duras busca trazer um elemento do testemunho que não é total nem necessariamente discursivo, mas que deve manifestar algo do corpo que não tem relação com a palavra (DERRIDA, 2004b, p. 528). Bourdil trata desse aspecto bruto em "La douleur":

Les mots et la tentation de la littérature, qui déroulaient leur propos sans problème apparent, laissent la place aux plaintes, aux cris, à "ça”, immaîtrisés, langage élémentaire, bestial ou instinctif de la douleur qui se révèle à elle-même. (BOURDIL, 1987, p. 225)

Nesse mesmo sentido, Sophie Bogaert (2014, p. 1334) cita Pierre Lepape: "Pur 'cri', La Douleur a la force 'd'écrits nus, comme recueillis à l'état naissant, au ras de leur effleurement, dans cette vérité primitive et pourtant mystérieuse que n'ont pas encore travestie les habits et les séductions du langage'" (grifos nossos). Nesse caso aparece, novamente, a expressão do grito que não é descrito pela escritora, mas expresso de outra forma, pela crueza de seu texto: "Écrire c'est ne pas parler. C'est se taire. C'est hurler sans bruit" (DURAS, 1993, p. 34). Por um lado, a secura da forma e a simplicidade da linguagem expressam a grande dificuldade em extrair do vivido um sentido elaborado, demonstrando igualmente os passos trôpegos da escritora na transformação do vivido em uma experiência coesa e uniforme. Por outro lado, talvez essa nudez e secura do texto sejam a estratégia encontrada de forma mais consciente pela escritora para tratar do horror, do abjeto, sem nos permitir gozar com ele. Nesse caso, esta forma seria o fruto de um julgamento ético e estético.

A secura dos textos transmite também o efeito de anestesia e paralisia diante do horror mencionado por Perec - "Dans tous les cas, monotone ou spectaculaire, l'horreur anesthésiait" ([s. d.] apud BORNAND, 2004, p. 29). No lugar de adotar uma linguagem afetada, excessivamente emotiva, a secura do texto transmite o embotamento dos sentidos que afetam a própria escritora, especialmente diante de Robert L. A forma de "diário" e os longos parágrafos de algumas entradas sugerem a ideia de um testemunho que não consegue se realizar em uma única sessão, mas em desabafos de longos fôlegos que não podem se sustentar por muito tempo, se interrompendo até outro dia ou outro momento, diferindo o transbordamento da emoção. Para Bornand (2004, p. 30), o livro de Duras é um daqueles em que ecoa o manifesto de Perec sobre o testemunho engajado que demanda do autortestemunha uma reflexão consciente sobre o ato da recepção pelo leitor, isto é, sobre o efeito provocado no leitor. 


\section{1}

Em relação ao aspecto corpóreo da escritura, que pudemos identificar na dimensão material dos manuscritos da obra, alguns elementos não textuais são de especial interesse por justamente não se derivarem da transformação operada pelo espírito e pelo logos. Primeiramente, devemos dizer que os textos ("La douleur", "Monsieur X. dit ici Pierre Rabier", "Albert des Capitales" e "Ter le milicien") a cujos avant-textes tivemos acesso, seja pelos originais ou por fac-símiles, tiveram suas primeiras elaborações escritas à mão. $\mathrm{O}$ aspecto manuscrito situaria a escritura, segundo Grésillon (1994), mais próxima do imediatismo do vivido. Outro aspecto interessante são as diferenças existentes entre os Cahiers de la guerre de Duras ("Cahier rose marbré", "Cahier presses du XXe siècle", "Cahier de cent pages" e "Cahier beige"). Os dossiês relativos aos cadernos que contêm os primeiros esboços do texto "La douleur" são bastante distintos entre si.

A partir de uma análise cuidadosa desses manuscritos, podemos tecer as seguintes considerações sob a perspectiva que nos interessa neste trabalho. Concluímos que as emoções são muito mais contidas e formatadas na escritura dos textos que relatam a espera por Robert Antelme, visto sua linearidade que não foge às pautas dos cadernos e que mostram poucas rasuras - mesmo porque não há muito espaço para elas. Além disso, pensamos que a forma de diário tenha sido adotada no meio do projeto desenvolvido nos "Cahier presses du XXe siècle" e "Cahier de cent pages", em uma tentativa de conter ainda mais essa escritura em uma forma definida, com uma cadência temporal que de outro modo não existiria, considerando que são pouquíssimas as rupturas no decorrer do texto. É possível que, no momento da escrita, a autora se esforçasse para controlar suas emoções, não se permitindo respiros em que estas pudessem transbordar.

Nos manuscritos referentes à primeira parte de "Pas mort en déportation" - que descreve as condições físicas de Robert Antelme ao retornar dos campos - e naqueles referentes à "L'horreur d'un pareil amour", nossa impressão é absolutamente diferente. Por não ser pautado, o caderno ("Cahier beige") acolhe o caos das emoções, em inscrições de natureza e temáticas muito variadas, além de fragmentárias. Deixa transparecer imensa oscilação nos humores e acolhe 0 excerto de "La douleur" que traria maior impacto e sofrimento, assim como o esboço do texto - que não viria a integrar a publicação de La Douleur - que conta uma das experiências mais sensíveis e traumáticas da vida da autora durante a guerra: a morte de seu filho no nascimento. Além disso, nenhuma das inscrições é tão longa quanto aquelas dos cadernos mencionados anteriormente, indicando o intenso sofrimento que não poderia ser sustentado por muito tempo. Finalmente, a autora permite que o caderno seja invadido pelos desenhos de seu filho, o que de certa forma ameniza a dor nele contida, assim como no próprio texto "L'horreur d'un pareil amour", em que a dor da narradora é contraposta ao sorriso do filho. Para Grésillon (1994), as rupturas, características do "Cahier beige" consistiriam em "gritos de emoção", marcas cambiantes e frágeis de uma individualidade.

Por fim, os primeiros esboços de "Albert des Capitales" e "Ter le milicien" têm como suporte o "Cahier Rose Marbré", um caderno semelhante ao "Cahier beige", não pautado. Suas notações de tempo indicam que Duras começou a redigi-lo antes dos outros cadernos, ainda em 1943. Contém, entre outros textos, uma longa narrativa autobiográfica de suas experiências na infância e adolescência na Indochina, inclusive sua relação com o chinês que se tornaria L'amant (DURAS, 2006, p. 29). Em geral, os textos são pouco rasurados, mas percebe-se que o ébauche de "Albert des Capitales" tem uma escritura menos fluida e é um pouco mais rasurado. Esse caderno também é de "coautoria" do filho de Duras que preencheu algumas de suas folhas com 


\section{1}

desenhos, inclusive na página que antecede as primeiras palavras do esboço de "Ter le milicien". Os desenhos demonstram que, embora Duras tenha começado a se dedicar à redação desse caderno ainda durante a guerra, alguns textos foram escritos quando algumas cicatrizes já haviam começado a se curar com o nascimento de Jean Mascolo. Há, inclusive, um pequeno texto sobre a espera de uma criança.

No livro publicado, o corpo assume o lugar da imagem no plano do conteúdo da narrativa, fruto da construção metafórica. Em "La douleur", encontramos a imagem peculiar, incontournable no debate da obscenidade e da manifestação da alma, que é a do corpo de Robert L. quando retorna:

Personne, en voyant cette forme, ne pouvait tolérer sa présence. Après avoir tant espéré qu'il revienne, son retour produisait des effets pires que s'il n'était pas revenu. On avait pu construire des images de sa mort, la plaine, le fosse, mais on détourne les yeux quand on le voit dans sa réalité (BOURDIL, 1987, p. 236).

A descrição feita pela narradora é fruto da transposição do sofrimento para o mundo das aparências, que de pronto demonstra a impossibilidade de fazê-lo de maneira harmônica, sem incorrer na obscenidade. $O$ deciframento de Duras, de acordo com nossa análise, seria na realidade a invenção de uma linguagem a partir do "empréstimo às palavras originalmente concebidas para corresponder ou a experiências dos sentidos ou a experiências da vida comum" (ARENDT, 1992, p. 79). Assim, em um primeiro nível de significação, esse é o retrato da corporeidade do sofrimento, que cala a razão na presença da dor e do impulso de indignação que the responde: o sofrer remete ao corpo em sua organicidade viva sob o signo da encarnação, que é testemunhada pela narradora.

No entanto, em contraste com essa degradação e o sofrimento animal, ganha destaque o que permanece de humano em Robert L.: trata-se de "lier [...] l'évidence de la douleur à celle de l'être humain" (BESSIĖRE, 2014, p. 24). Segundo Eliane Robert Moraes (2000, p. 150), "se compartilhamos as qualidades do que é humano [...] somos obrigados a aceitar [...] que, em meio aos escombros de uma guerra, os moribundos, os corpos mutilados, os feridos, os deformados, permanecem sendo seres humanos, apesar da animalidade de seu sofrimento". Isso é condizente com a reivindicação à espécie feita pelo livro de Robert Antelme, L'espèce humaine, que também destaca a degradação de seu próprio corpo e de seus colegas deportados no período de internamento.

A deterioração do corpo dos internados não apenas fazia parte da estratégia de matar pouco a pouco de fome, com custo mínimo e aproveitamento dos trabalhadores, mas se tratava também e principalmente de estabelecer uma distância entre os agentes alemães e Kapos bem nutridos, de bochechas rosadas, e os detentos que personificavam em sua aparência a "degradação da raça" da qual eram acusados: "A preparação de cadáveres vivos [...] ou a sua 'desvairada fabricação', com sua aparente inutilidade, visava a transformar a própria natureza humana" (PERRONE-MOISÉS, 2012, p. 141).

Assim, a decadência do corpo de Robert L. constitui também, em um segundo nível de significação, a imagem fruto da transposição metafórica da própria ideia de degradação da natureza humana que foi tentada nos campos de concentração. A afirmação de Montesquieu em $O$ espírito das Leis ([s. d.] apud ARENDT, 2008, p. 339) - "O homem [...] é igualmente capaz de conhecer sua própria natureza, quando esta lhe é mostrada, e de perder até o sentimento, quando a roubam dele" -, encontra sua imagem no retrato da fome infinita de Robert $L$. : 


\section{1}

On le laisse seul devant la nourriture. [...] II n'a pas de préférence marquée pour les plats. De moins en moins de préférence. II avale comme un gouffre. Quand les plats n'arrivent pas assez vite il sanglote et il dit qu'on ne le comprend pas. [...] Pendant quinze jours, vingt jours, je l'ai regardé manger sans pouvoir m'habituer non plus, dans une joie fixe. II ne me voyait pas. II m'avait oubliée. (DURAS, 1985, p. 77-78)

Nesse sentido, Robert se tornaria o corpo sacrificial dado em nome do progresso da história: "[p]or meio de uma espécie de lógica sacrificial [...] que consiste em produzir continuamente, pela força de seu avanço, algo que seja substituído, abandonado às margens [...]" (ZAMORA, 2012, p. 106). Loignon estabelece uma comparação entre o corpo de Robert L. e o corpo sacrificial de Cristo, cuja Paixão acompanhamos pelos olhos da narradora. Se essa comparação não é explicitada em La Douleur, ela o seria no texto Écrire (DURAS, 1993, p. 133), em que a autora declara que "lui, le Christ, a été assassiné comme un déporté politique".

Martin Crowley (2010, p. 104) aponta que "refuser, à l'époque la reprise prétendument thérapeutique d'un traumatisme passé explicitement relié au temps de la libération, c'est refuser le récit résistantialiste sur lequel s'appuyait le pouvoir gaulliste renaissant”. Essa ideia articula-se com a expressão da narradora que rechaça ferrenhamente o discurso gaullista que apresenta a França como vitoriosa e resistente em detrimento do reconhecimento da solidariedade ao sofrimento das vítimas da ocupação nazista. A obscenidade do corpo, portanto, responde também à necessidade de colocar diante dos olhos de todos os detritos rejeitados da guerra, seus destroços não reconhecidos pelo discurso oficial. Duras descreve uma cena que espelha as inúmeras situações descritas em L'Espèce humaine, em que a distância que separa a aparência dos deportados e dos alemães e seus aliados é evidente; no entanto, dessa vez ela refere-se aos gaullistas que recepcionam os voluntários do Service de Travail Obligatoire e os deportados:

On se demande d'où sortent ces gens, ces vêtements parfaits après six ans d'occupation, ces chaussures de cuir, ces mains, ce ton altier, cinglant, toujours méprisant que ce soi dans la fureur, la condescendance, l'amabilité. [...]

Elles [les volontaires S.T.O.] sont très sales et elles ont le visage décomposé. Deux d'entre elles ont un ventre énorme. Une autre femme officier regarde, un peu à l'écart. [...] La colonelle a dû leur apprendre qu'elles étaient des ordures.

Tout à coup débouchent du couloir d'entrée deux scouts qui portent un homme. [...] L'homme est habillé en civil, il est rasé, il a l'air de beaucoup souffrir. II est d'une étrange couleur. II doit pleurer. On ne peut pas dire qu'il est maigre, c'est autre chose, il reste très peu de lui-même, si peu qu'on doute qu'il soit en vie. Pourtant non, il vit encore, son visage se convulse dans une grimace effrayante, il vit. [...] On ne peut pas savoir s'il est aussi vieux que ça, peut-être qu'il a vingt ans, on ne peut pas savoir l'âge. Le ministre s'approche [...], il lui tend la main, le vieillard la prend, il ne sait pas que c'est la main du ministre. Une femme en uniforme bleu le lui crie: "C'est le ministre! Il est venu vous recevoir!". (DURAS, 1985, p. 23-31)

Assim escreve Bourdil (1987, p. 215) a propósito dessa cena: "On a rendu propres les déportés, pour les rendre acceptables, le temps au moins que le ministre leur parle. Peu importe, à lui et 


\section{1 -}

aux autres, ce qu'il dira, ses mots sont suffisantes parce qu'ils ne s'adressent pas à des hommes, mais à des suffrages". Desse modo, o retorno à pátria não os devolve à humanidade; ao escapar dos campos, os deportados percebiam que a alienação do homem em relação ao semelhante e ao mundo não era atributo exclusivo dos nazistas.

$O$ corpo de Robert $L$. pode ser entendido metaforicamente - se considerarmos, como Bessière (2014), que no âmago da obra de Duras esteja a questão representacional - como um símbolo da própria (não) contraposição entre o interior e o exterior, a alma e o corpo, o sofrimento e sua expressão, que se confundem em determinada medida, uma vez que o corpo é onde aflora e ancora-se o sofrimento, não só corpóreo como psíquico: "Il a disparu, la faim est à sa place" (DURAS, 1985, p. 77). As aparências, segundo Arendt (1992, p. 30), "têm a dupla função de ocultar algum interior e revelar alguma 'superfície' [...]. Em função da lacuna entre interno e externo, entre base da aparência e aparência [...] o que permanece sempre verdadeiro é que 'por dentro somos todos semelhantes"'.

Nesse caso, a aparência de Robert borra a fronteira entre o interior e o exterior, fazendo com que aquilo que deveria ser oculto e protegido, como os órgãos internos, os dejetos humanos, apareça à luz do dia, ao público. Além disso, como todos somos iguais internamente, a interioridade desse corpo revela aquilo que há de comum aos homens, mostrando ao mesmo tempo que as funções orgânicas mais básicas nos aproximam dos animais. As afecções da alma em seu estado puro também não distinguem os homens, o que os distingue é precisamente a forma como essas emoções são transformadas em palavras e, assim, significadas. A dor em estado bruto rouba todas as características próprias também da narradora, a ponto de referir-se a si própria como outra, desconhecida: “Je n'existe plus. [...] Qu'est-ce qu'elle attend en vérité? Que se passet-il dans cette chambre? Qui est-elle? Qui elle est, D. le sait” (DURAS, 1985, p. 50).

Por outro lado, o que faz com que Robert L. seja reconhecido pela narradora, a qual, assim como Penélope, não reconhece de pronto o marido - "Mas agora não me odeies por isto nem te indignes, por que não te saudei com afeto tão logo te vi" (HOMERO, 2014, XXIII, p. 576). -, é o seu sorriso - "C'est à ce sourire que tout à coup je le reconnais [...]. Et puis le sourire s'évanouit. Et il redevient un inconnu" (DURAS, 1985, p. 69). O sorriso é interpretado por Arendt como uma expressão corpórea da alma, e por Duras como um traço que evoca algo além da presença corpórea, algo mais essencial, mais profundo (BAJOMÉE, 1989, p. 144-145), o que nos faz intuir que o corpo também seja portador de uma linguagem e identidade próprias, assim como o corpo do texto, em que algumas marcas formais revelam o estilo e a identidade do escritor.

Em "La douleur", a dor é responsável por desfigurar o corpo, humano e textual, tornando-o irreconhecível. O corpo da narradora torna-se, no decorrer da espera, um reflexo do corpo debilitado do marido. Essa ligação da narradora a Robert L. perdura durante sua recuperação: "Moi aussi, je recommence à manger, je recommence à dormir. Je reprends du poids. Nous allons vivre. Comme lui pendant dix-sept jours je n'ai pas dormi, du moins je crois n'avoir pas dormi” (DURAS, 1985, p. 78).

Contudo, à medida que ele se recupera fisicamente, os personagens distanciam-se, demonstrando que o que a narradora estava a mimetizar não era Robert L., mas a morte. $O$ distanciamento restabelece seus traços individuais, mas acaba por criar um abismo que se revela intransponível, culminando na separação depois da recuperação de Robert L. Fica claro que o amor entre eles persiste de alguma forma, pela cumplicidade de seus olhares, mas algo irremediavelmente se rompeu. 


\section{1 -}

O retorno de Robert L. é marcado pela necessidade de a narradora ficar diante do corpo cadavérico do marido. Como vimos, o detalhamento das descrições físicas estabelecem o abismo entre o corpo do deportado e daqueles que o circundam (BORNAND, 2004, p. 142). O que antes unia os dois no imaginário da narradora - a semelhança física - agora os separa: "Pendant dixsept jours, l'aspect de cette merde resta le même. Elle était inhumaine. Elle se séparait de nous plus que la fièvre, plus que la maigreur, les doigts désonglés, les traces des coups des S.S." (DURAS, 1985, p. 73).

Um recurso estilístico que marca a separação de Robert L. é a utilização do pronome "il" para referir-se a ele, isoladamente, em oposição ao pronome "on" para referir-se a ela e às demais pessoas. Como observa Bornand (2004, p. 142-143), o pronome "tu", que estabeleceria uma relação dialógica com Robert L., não é jamais utilizado, enquanto que o pronome "il” estabelece a relação entre um sujeito que observa e um objeto que é observado, sendo esse objeto não Robert L., em toda sua identidade, mas apenas sua dimensão física, seu corpo. Percebemos, ainda, que o discurso direto é utilizado somente uma vez para dar voz ao personagem.

Outro corpo apresentado em sua nudez, contrastando com o de Robert L., é o do colaboracionista torturado no texto "Albert des Capitales". Seu corpo se contrapõe ao do deportado, assim como, em L'Espèce humaine, os corpos dos agentes, Kapos e Meisters, apareciam em contraste com o dos deportados políticos. O corpo nu do colaboracionista é "gras et rose dans la lueur de la lampe-tempête" (DURAS, 1985, p. 154). Como depreendemos de ambos os livros, a robustez e o rubor são sinal de que se usufrui de posição favorável em uma época de guerra, sinal de que se colabora com os vencedores. Apenas assim se goza de boa saúde. O corpo do colaboracionista, portanto, antes mesmo deste proferir uma palavra sequer, já denuncia sua posição. Do mesmo modo que o corpo de Robert L., por mais debilitado que esteja, por mais terrível que pareça, porta a dignidade daquele que não colaborou com os alemães.

Em determinado momento, Duras desumaniza completamente a figura do "donneur d'hommes", que "n'était déjà pas un homme comme les autres", equiparando-o a um porco, o que nos remete novamente à Odisseia, quando a feiticeira Circe transforma a tripulação de Ulisses em porcos. De Chalonge (2010, p. 214) questiona se por acaso essa desumanização não seria justamente para contrariar a tese de Robert Antelme, segundo a qual se pode "tuer un homme", mas não se pode "le changer en autre chose" (ANTELME, 1957, p. 241). No entanto, a crítica percebe que, em La Douleur - e cremos que na obra de Duras em geral -, toda tese resiste à edificação, com o que concordamos, não apenas porque fica ambíguo se é o personagem ou o narrador que assume a posição em relação àquilo que se diz sobre a tortura, mas também porque percebemos que, diferente de Robert L., Duras não procura transmitir uma lição aprendida a partir de suas vivências, como um conhecimento precioso, mas procura expressar os sentimentos rancorosos de sua alter ego no momento do vivido, como se reconhecesse, emprestando as palavras de Derrida (2004a, p. 545), que "se laissait emporter, de façon coupable, par la colère et l'indignation, même si cette colère se donnait des airs de colère du juste".

A razão para o discurso violento extrapolar os enunciados da protagonista é que ambas, narradora e personagem, são representações da mesma pessoa. Ademais, a intensidade da cena da tortura é produzida pelo fato de personagem e narradora estarem inseridas no tempo presente da narrativa, sem que se tome a devida distância dos acontecimentos. Possivelmente, Duras 


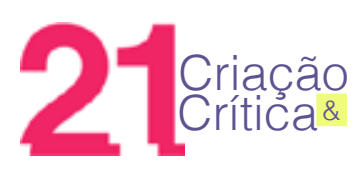

escolhe nos colocar no presente da cena para que o impacto da violência de tortura não seja amenizado ao leitor, o que seria, em determinada medida, irresponsável.

\section{O estilo visual e o presentismo}

Duras é uma mestra da imagem, em seus filmes como em seus livros. (PERRONE-MOISÉS, 2013)

A difusão da memória da Segunda Guerra Mundial para o grande público, devemos lembrar, foi estreitamente ligada ao cinema, que tem um amplo alcance e impacto por meio da imagem mostrada, explícita, e que, por esse mesmo motivo, acaba por despertar uma preocupação ética com a obscenidade. Em 1961, Jacques Rivette escreveu no Cahiers de Cinema (n. 120) um artigo intitulado "De l'abjection", que versava sobre o filme Kapo, de Pontecorvo, argumentando que, por ser a presença absoluta, o realismo absoluto, impossível, toda tentativa nessa direção seria antiética e, portanto, toda a abordagem tradicional do espetáculo "relève du voyeurisme et de la pornographie", seja porque a "realidade" apresentada é necessariamente suavizada e o espectador a crê suportável ou escapável, seja porque o espectador, se habituando ao horror, o torna parte dos mœurs.

Essa preocupação também existe em relação aos textos literários, e está intimamente vinculada a um estilo que, por meio de simulacros visuais, coloca diante de nós as imagens de forma detalhada e que é justamente o estilo característico dos primeiros romances de Duras, que reaparece na década de 1980, inclusive em La Douleur. No entanto, a literatura, por mais visual que seja, sempre recorrerá a uma imagem retórica, isto é, que demanda esforço imaginativo e engajamento por parte do leitor para se criar uma imagem mental, ao passo que a imagem mostrada pode chegar ao receptor mesmo de maneira involuntária.

A impossibilidade da representação visual está relacionada à impossibilidade de compreender o horror, tendo em vista que a tradição ocidental, especialmente a metafísica clássica, adota uma concepção de verdade apoiada na visão como modelo para os demais sentidos, ou na metáfora da visão para a definição da verdade (LEBRUN, 1988). Tal metáfora está relacionada com um modelo de verdade apoiado na autoevidência da existência de um objeto que está diante de nossos olhos, ao passo que a verdade ligada à metáfora da audição, característica da religião hebraica, é invisível e exige obediência ao enunciado (ARENDT, 1992, p. 87). Entretanto, no caso de um "estilo visual" de escritura, estamos diante de uma verdade que conjuga esses dois aspectos: o auditivo (ou discursivo) e o visual, que conjuga as duas pontas do testemunho, o témoin-témoin (witness) e o témoin-témoignant (testimony) (DERRIDA, 1993, fl. 2).

Para a escritora, a imagem interior ("invisível") possui uma virtude em relação à fotografia, qual seja, a de representar um "absoluto", no sentido de que a palavra não opera um fechamento da representação, mas uma abertura em vista de seu caráter plurissemântico e de sua "insuficiência" em relação à imagem, de sua impossibilidade última de ser imagem. A palavra depende da imaginação do leitor para a composição de outra imagem mental; a origem da imagem que se forma, portanto, já é múltipla, colaborativa.

Em uma narrativa que privilegia aspectos visuais, o narrador, enquanto observador, em contraste com o narrador ouvinte, experimenta o presente não como um momento que passa, mas como uma dimensão dentro da qual as coisas podem ser observadas em uma dada permanência. Desse modo, 


\section{1 -}

a dimensão visual possui uma íntima ligação com o presentismo, ou seja, com um presente permanente (ARENDT, 1992, p. 86), o que encontramos no estilo durasiano (BAJOMÉE, 1989, p. 112).

É possível afirmar, portanto, que um estilo visual de escritura tem algo comum ao cinema: a adoção necessária de um ponto de vista, de um ângulo. No entanto, temos que questionar a afirmação de Rivette de que o ponto de vista adotado deriva necessariamente de uma escolha (choix) do diretor, escolha esta formal, mas também ética. Quanto se trata de uma literatura de forte teor testemunhal, como é o caso de grande parte dos textos de La Douleur, precisamos nos perguntar - sem jamais saber a resposta - se o sobrevivente, aquele que vivenciou os eventos relatados em todo seu horror, teve de fato essa escolha ou se foi a única maneira pela qual ele pôde abordar os eventos e as emoções.

Quando Duras, por exemplo, adota o ponto de vista de um terceiro para descrever a cena de tortura que ela própria teria conduzido, criando uma personagem que age em seu lugar, é possível que somente assim ela conseguisse olhar para si mesma, a partir do ponto de vista do outro. Mesmo porque, naquele momento, talvez ela considerasse que sua identidade tivesse se cindido.

O tempo presente da narrativa seria outro elemento formal que contribuiria para o aspecto obsceno de alguns fragmentos, algo comum a outros textos de Duras publicados no mesmo período, como L'amant: “Trata-se de uma 'presentificação' do passado, sempre atual na memória da narradora, e de uma apresentação 'ao vivo', que aproxima o leitor, visando incluí-lo" (PERRONEMOISÉS, 2013). Lembramos que outro corpo colocado em evidência em "La douleur" é o da própria narradora. É por meio dele que descreve suas sensações enquanto témoin-témoin (witness), possibilitando que o leitor entre em comunhão não apenas com o narrador que porta testemunho, mas também com o narrador que vive e testemunha no presente. Bessière (2014, p. 23) ressalta, na literatura durasiana dos anos de 1980, a "présence de l'écrivain(e) (dès lors qu'elle dit que ces romans sont les romans de sa vie) et la mise en évidence de son explicite rôle de medium et de personnage percevant, ainsi que ces rôles ont été définis".

Essa "presentificação" aproxima a narrativa à "memória da fera" de Bataille, que estaria restrita ao imediatismo do acontecido, negando qualquer possibilidade de abertura para um devir ou de se propor um sentido para o acontecimento e o horror. O efeito de "memória da fera" gerado pelo presentismo não condiz com a interpretação da narrativa como possibilidade de construção da experiência, como uma abertura para a compreensão, produzindo uma aporia. O que nos leva a pensar que talvez o presente seja uma tentativa de restituir o sentido que reside no imediato: "Avec sa jeunesse, le sens a fui. La douleur se vit au présent. La littérature, en la rendant éternelle, la vide de son intensité" (BOURDIL, 1987, p. 216).

Não à toa, no texto "La douleur" a narração no presente está ligada à estrutura do diário e à espera. O diário é caracterizado como a escritura do presente por excelência, e a espera é um estado que não permite à narradora abrir-se para nenhum devir, uma vez que a definição do futuro, de algum projeto futuro, depende da sobrevivência ou morte de Robert L. A espera, portanto, abole o tempo e o espaço, e captura a narradora em um presente absoluto.

Existem dois tempos paralelos na narrativa da espera de Robert L.: o tempo que corre - onde habita De Gaulle e outras figuras da História - e o presente duradouro, o eterno presente, onde vive a narradora e aquelas que esperam: “Je n'ai plus jamais faim. [...] il n'y a que nous qui attendions encore, d'une attente de tous les temps, de tous les lieux du monde: celle des hommes au retour de la guerre" (DURAS, 1985, p. 59-60). A espera em um tempo e lugar eternos eleva o testemunho de 


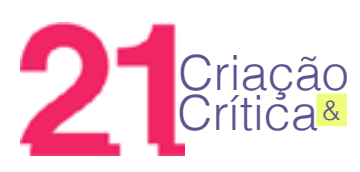

Duras a uma dimensão não apenas universal, mas também permanente e natural, como algo que sempre existiu. Diante do ineditismo da experiência totalitária e da solidão por ela imposta, há um núcleo que pertence à natureza da guerra que a autora caracteriza como seu ennui.

O retorno de Robert L. rompe com o ennui e traz a narradora de volta ao tempo que passa. Quando recebe a notícia da sobrevivência do marido e depara-se com seu corpo, todo o ineditismo do massacre totalitário a arranca da espera que poderia acontecer a qualquer tempo: "Celui qui revient, elle ne veut pas le voir. Mais quand elle l'entrevoit, toute la guerre la saisit d'un coup" (BOURDIL, 1987, p. 231-232). De Chalonge (2010) aponta que, paradoxalmente, o diário é a forma da ausência, enquanto que a presença de Robert L. demandará a retomada da distância do récit, uma vez que a narrativa permite que uma experiência traumática seja vista a partir do recuo temporal, protegendo o narrador - assim como o leitor - do encontro direto com uma cena "trop réel", o que, podemos dizer, atenua seu caráter obsceno.

\section{$O$ retraimento frente ao mundo}

Em oposição aos textos elaborados nos Cahiers de la guerre, escritos nos anos seguintes ao término da guerra, os textos posteriores conseguiram integrar de modo mais harmônico a experiência da guerra à vida. No entanto, muitas vezes, isso ocorre com o reconhecimento de que a única maneira de se compreender a vivência em uma época na qual a espécie humana retrocedeu ao infinito os limites da inumanidade (LE PAPE, 1985, apud BOGAERT, 2014, p. 1334) é, paradoxalmente, admitindo sua incognoscibilidade, e até mesmo sua incompreensibilidade: "on ne peut pas connaître ce que l'on voit, où la connaissance est désespérée de connaître" (FERNANDES, 1986, p. 146). Heidegger (2008) afirma que, caso algum dia o homem encontre o caminho para a proximidade do ser, deverá aprender a existir no inefável.

A pretensão de desnudar e retratar o horror talvez seja como fitar os olhos da medusa ou olhar para a face de Deus e representá-lo: "quem fitou a górgona, não voltou para contar, ou voltou mudo. [...] [A]ssim como ninguém jamais voltou para contar sua morte" (LEVI, 2016, p. 66-67). Essa tentativa de se dar a ver, ou de trazer a alma à superfície, culminaria necessariamente em um grito, na loucura e na obscenidade daquilo que não se mostraria autenticamente. O eidos, assim, não poderia jamais ser atingido, sendo apenas um princípio formal, uma vez que é da ordem do eterno, do sublime e do não mundano. A abordagem que reconhece os limites dessa representação resulta em um retraimento frente ao objeto. Assim, Duras percorre o caminho da tentativa de apreender e desvelar aquilo que não se mostra de modo direto ou autêntico. Ela percorre o caminho que vai desde o retrato obsceno até a expressão que apenas toca o contorno das coisas.

Segundo Blot-Labarrère (1992), Duras, principalmente em seus escritos mais tardios, evitava a banalização do inefável, sabendo que tentar nomeá-lo seria da ordem do "sacrilège. Presque sacrificiel" (DURAS, 1989, p. 55). Nesse sentido, a própria escritora confessa que, nos livros anteriores a Moderato Cantabile ou até mesmo a Hiroshima mon amour, faltava espaço em que pudesse se produzir um buraco ou um branco na representação (DURAS; GAUTHIER, 2014, p. 8).

Ricoeur (1991, p. 341) considera o horror como uma "vénération inversé", isto é, que desperta um sentimento análogo ao da admiração, como o que temos diante de tudo aquilo que nos parece inédito. Desse modo, o horror não seria passível de uma explicação universalizante porque dissolveria a singularidade do evento e evocaria uma resposta puramente emocional. Apenas a ficção daria conta de produzir uma "illusion contrôlée [...] pas destinée à plaire, ni à distraire. 


\section{1}

Elle est mise au service de l'individuation exercée par l'horrible comme par l'admirable". Embora consideremos que todos os textos da obra tenham uma carga ficcional, "quelles que soient les données autobiographiques avouées" (BESSIĖRE, 2014, p. 22), o caráter declaradamente ficcional vai progressivamente se intensificando do começo ao fim do livro, sendo que os dois últimos textos constituem um caminho mais indireto ao horror, que evita encará-lo.

O distanciamento geográfico do centro de Paris, em "L'Ortie brisée", coloca os personagens à margem dos acontecimentos - "Là-bas, c'est le Petit-Clamart. - II montre la direction du tas de ferraille et d'orties -, ici c'est encore Paris. Enfin, en principe..."' (DURAS, 1985, p. 199). E o fato de Aurélia, em "Aurélia Paris", observar os acontecimentos de sua janela - que em muitos momentos permanece fechada pela cortina -, ouvindo o barulho dos aviões, também denota o distanciamento e a abordagem por meio de um caminho que apenas tangencia o horror.

O início de "Aurélia Paris" é carregado de uma atmosfera etérea de fantasia e conto de fada da pequena menina presa na torre -, que aos poucos vai se dissipando para dar lugar à guerra, sem, contudo, desaparecer totalmente:

Aujourd'hui, derrière les vitres il y a la forêt et le vent est arrivé. Les roses étaient là-bas dans cet autre pays du Nord. La petite fille ne les connaît pas. Elle n'a jamais vu les roses maintenant mortes ni les champs ni la mer.

La petite fille est à la fenêtre de la tour, elle a écarté légèrement les rideaux noirs et elle regarde la forêt. (DURAS, 1985, p. 209-210)

Para além da fiçção, nesse texto Duras entra no terreno do alegórico, do mito. Tanto Aurélia quando o estrangeiro de "L'Ortie brisée" são personagens que tendem ao alegórico. Ao longo do livro encontramos personagens com essa tendência, como a filha de Mme. Kats - que será transformada em personagem alegórico em outros textos de Duras -, Thérèse, Ms. X. ou mesmo a narradora dos dois primeiros textos, e o próprio Robert L. Mas, nos textos "inventés", isso fica ainda mais claro. A construção do mito de Aurélia Steiner, a pequena menina judia abandonada ou nascida em Auschwitz, personifica e condensa todos os personagens judeus de Duras, do mesmo modo que alguns mitos, para se universalizarem, reúnem diversas estórias e versões regionais.

O mito, para Heidegger (2008, p. 92-93), consiste em uma forma primordial de buscar a verdade, e é a forma assumida por Duras e pela literatura de modo geral: "Muito diverso de um devaneio fantasioso, o mito é um sistema simbólico rigorosamente formalizado. O modo literário de buscar a verdade continua sendo o modo simbólico do mito" (PERRONE-MOISÉS, 1990, p. 106). O que buscamos realizar aqui é o deciframento de alguns elementos desse sistema simbólico em La Douleur, desde os textos que não conteriam, em um primeiro olhar, nada de simbólico ou metafórico, aos quais a própria autora nega o status de literatura, até aqueles em que o teor alegórico é bastante evidente, estabelecendo um caminho mais indireto, mas não menos verdadeiro, para o sentido das coisas.

Retornamos à ideia, mesmo nos textos repletos de dados autobiográficos, de que é preciso estar atento para identificar a verdade da dor, que "ne se confond pas nécessairement, faut-il répéter, avec la vérité des faits rapportés" (BESSIÈRE, 2014, p. 22). Toda vez que a palavra assume a função de mero signo, a relação entre o escrever e o pensar não passa de uma relação instrumental, que é 


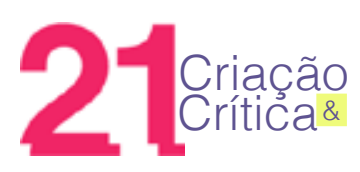

justamente o que se deve evitar na literatura posterior a Auschwitz, quando toda a criação humana, e o próprio ser humano, foram instrumentalizados para acelerar o "destino da humanidade".

Observamos, portanto, que a questão ética e a forma de se buscar a verdade estão intimamente relacionadas. No caminho da busca pela verdade e pelo sentido dos acontecimentos, Duras experimenta diversas formas e monta aos poucos seu sistema simbólico, que, por sua vez, nunca se fecha, nem se deixa apreender por completo. Nesse sentido, Maria Luiza Berwanger da Silva (2014), trata da perceptibilidade daquilo que a princípio não seria visível, do espetáculo que somente se dá a ver em um "interstice de perceptibilité" na obra de Duras.

\section{Responsabilidade, reconhecimento e mal}

A questão da ética da representação está ligada de certa forma à promessa de veracidade que define o testemunho como um enunciado performativo, como já expusemos, e com a responsabilidade da testemunha enquanto sobrevivente em relação ao mundo, que se constitui como um compromisso da testemunha consigo própria e com o outro: "Responsabilité de l'auteur, implication du lecteur sont les deux termes fondamentaux de l'acte de communication qu'est la littérature, la forme esthétique assurant l'échange entre les partenaires de l'acte de lecture" (BORNAND, 2004, p. 26).

De acordo com Seligmann-Silva (2003, p. 57), os primeiros documentários realizados no imediato pós-guerra eram extremamente realistas, o que perversamente gerava uma sensação de descrédito nos espectadores. A saída teria sido a passagem para o estético e, com isso, a desconstrução da historiografia tradicional, incorporando elementos antes reservados à "ficção". Essa leitura estética opor-se-ia a uma musealização do ocorrido, mantendo o passado ativo no presente, o que é coerente com seu caráter performativo e com a relação do testemunho com o mundo que o recepciona.

No caso de La Douleur, também há o movimento de uma escritura mais "realista" para uma mais "ficcional", sem que nenhum desses aspectos esteja presente de forma absoluta. Nos textos que foram escritos logo após a guerra, a ilusão de realidade vai mais longe, especialmente em “La douleur": "C'est néo-réaliste comme la littérature de ce tempslà. Mais pas La Douleur. Là, la réalité est tellement terrible qu'elle en est irréaliste” (DURAS, 2014, p. 788).

É como se o testemunho, para engajar seus destinatários e legitimar-se como verídico, firmando um pacto de veridicção, precisasse criar a ilusão constativa da realidade dos fatos. Aqui entram em conflito noções de realismo que são afeitas a duas concepções distintas de literatura engajada, sendo a primeira a de um realismo marxista - professado por Sartre - e, a segunda, de um realismo dissimulado - professado por Perec. La Douleur se aproxima deste último, na medida em que se compromete com uma "ancrage dans l'actualité historique, mais un ancrage dissimulé, littéraire” (BORNAND, 2004, p. 24).

No momento da publicação de La Douleur, após Duras ter recebido o prêmio Goncourt por L'amant, os críticos se perguntavam: "verdadeiro ou falso?", "teria ela retocado os originais?" (BOGAERT, 2014, p. 1328). Parte da crítica, portanto, deixou que a dúvida sobre a autenticidade dos originais de La Douleur - que é uma questão legítima, que diz respeito à sua gênese, ao contexto de produção do texto - contaminasse por completo o sentido e o compromisso de "faire vrai" dessa literatura, não se engajando com a crença necessária para que o "testemunho" pudesse produzir seus efeitos. 


\section{1}

Todavia, em vista do caráter não probatório do testemunho, essa questão só é relevante para a veracidade testemunhal na instauração do pacto de leitura, aquele entre a testemunha e seu destinatário. No caso de La Douleur, como já exposto, o pacto de leitura não gira em torno da promessa de fidelidade aos fatos. Nesse sentido, a verdade por ela buscada pretende, antes, ser fiel a outros elementos não factuais, assim como à tentativa de um deciframento do sentido desses elementos por meio da escritura, quer na forma de um diário, o que confere ilusão de simultaneidade do testemunho aos fatos vividos, quer em textos declaradamente ficcionais, que obtêm a confiança e a crença do leitor na veracidade que se pretende expressar, em formas que ultrapassam a ilusão de fidelidade aos fatos vividos. Uma das formas pelas quais Duras estabelece o pacto de veridicção do testemunho em La Douleur, é a representação literária que serviria para a aproximação da morte e do sofrimento do outro, da violência e do desejo do outro, incitando o reconhecimento.

O medo da mimese, o medo da perda do eu que caracteriza o pensamento esclarecido e o ideal nazista de indissolubilidade de uma identidade una, seria contraposto pela aproximação do outro até a dissolução dos limites fixos e claros do ego. A dor seria experimentada e representada como uma espécie de comunhão entre aquele que sofre, aquele que percebe e o leitor: "En devenant cet autre qu'est Robert L., en écrivant sur et depuis son corps souffrant, la narratrice a quelque chose d'une mystique" (LOIGNON, 2003, p. 269). A obra poderia ser vista como um lugar de encontro com o outro. Todavia, frequentemente o outro tem a face não apenas da vítima, mas também do algoz. Ou melhor, não fica claro quem ocupa essa posição, principalmente em "Monsieur X. dit ici Pierre Rabier", "Albert des Capitales" e "Ter le milicien".

No primeiro, se estabelece uma improvável proximidade entre a vítima e o responsável por seu tormento, e cada um deles detém o poder de provocar a morte do outro. No final desse récit, o testemunho de Duras no Tribunal de l'épuration é decisivo para a condenação do gestapista à pena capital. Ela acaba entrando no terreno próprio de Rabier: a morte. Nos outros dois textos, o desejo de infligir dor e o desejo erótico são responsáveis por essa aproximação e confusão. Segundo Bogaert (2014, p. 1334-5):

[...] la proximité de la victime et du tortionnaire est donc l'une des armatures les plus solides de La Douleur [qui] n'est pas guidée par une intention morale, mais éthique - celle de montrer que, dans des situations telles que celle de la guerre, la frontière entre le bien et le mal s'abolit, ou à tout le moins s'estompe (grifos nossos).

Para Bornand, Duras leva o conceito de irredutibilidade e indivisibilidade da espécie humana expresso no livro de Robert Antelme, L'Espèce humaine, até o paradoxo: “[...] l'espèce humaine étant indivisible, il n'y a pas de frontières morales entre le bourreau et la victime, l'individu peut passer d'un rôle à l'autre: c'est ainsi qu'après la libération, les résistants pratiquent à leur tour la torture et les exécutions" (BORNAND, 2004, p. 143).

Essa permeabilidade entre as posições de vítima e carrasco indica, nos passos de Arendt, que naquele momento a moral sequer servia de barreira confiável entre o bem e o mal; mostra a que ponto os valores até então estabelecidos sofreram uma completa desvalorização, que afetou não apenas os membros do regime nazista, os opressores, como também os oprimidos. Aliás, segundo a avaliação da pensadora, o único novo princípio moral, proclamado nos tempos modernos, seria a negação da moralidade como tal. O regime nazista teria introduzido um novo sistema de 


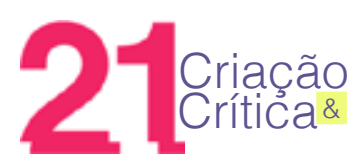

valores e projetado com sucesso sua legislação em concordância com ele, o que provava que não era preciso ser nazista convicto para se adaptar e esquecer-se, da noite para o dia, das convicções morais de outrora (ARENDT, 2004, p. 117-118)

A questão ética expressa nessa interpenetração do bem e do mal está profundamente vinculada com a questão da representação mimética, como mostra Derrida (2005, p. 37-42): o deus da escritura - Thot - seria também o deus da morte e da Lua. Sua figura se opõe a de seu pai, o Sol, a vida, repetindo-o ou tomando seu lugar. Curiosamente, Thot é o deus da passagem entre os opostos, o movimento subversivo da substituição. Distinguindo-se do seu outro, ele o substitui, assim como a representação substitui o real, a ficção a realidade, a memória o evento, a escrita o logos, as vítimas substituem os algozes, o mal substitui o bem e vice-versa. A interrupção da passagem entre os valores contrários seria, para Derrida (2005, p. 45), um efeito do platonismo: "ora, essa ambiguidade, Platão [...] quer dominá-la, dominar sua definição na oposição simples e nítida: do bem e do mal, do dentro e do fora, do verdadeiro e do falso, da essência e da aparência" (DERRIDA, 2005, p. 50).

Loignon (2003), ao tratar da escritura durasiana em La Douleur, nota que esta, em um primeiro momento, aponta barreiras e fronteiras, para então transpô-las e borrá-las. Duras estabelece dois campos claros: de um lado, os resistentes, prisioneiros, deportados e aliados; do outro, os colaboracionistas, voluntários S.T.O., milicianos e nazistas. A narradora, porém, parece incapaz de se situar entre esses dois campos, uma vez que rapidamente se percebe que "cette division entre Bien et Mal [...] s'avère inopérante. La douleur décrit une zone de nondroit” (LOIGNON, 2003, p. 266). Ao mesmo tempo que a narradora descreve fronteiras, as situações narradas por ela as tornam porosas, impraticáveis.

Agostinho (2002, p. 171), ao tratar da interpretação das sacras escrituras, que seria uma das formas de se olhar para os textos qualificados como "sagrados" por Duras, indica que a imensa variedade dos "costumes" deve ser levada em consideração na hermenêutica desses textos. Daí não se deve, porém, supor que não há bem e mal absolutos. No entanto, o preceito ao qual Agostinho faz referência como balizador universal da boa conduta dos homens é baseado muito mais em um parâmetro ético do que moral - "Tudo quanto, pois, quereis que os homens vos façam, assim fazei-o vós também a eles" -, e, portanto, não define uma conduta particular como boa ou má. O referido preceito depende do julgamento individual para sua realização, confiando na faculdade de julgar dos homens em tempos de crise, quando padrões morais e religiosos são colocados à prova.

Desse modo, tentar definir uma dada conduta ou um dado modelo de homem como representante universal do bem absoluto, semelhante ao que fora feito pelos nazistas, conduz às proximidades do mal absoluto. Nesse sentido, La Douleur, a partir do movimento mesmo de sua escritura até o conteúdo do relato, se constituiria como uma crítica ao modo de pensar dicotômico, que tende à simplicidade do absoluto.

O mal estaria vinculado a uma tentativa de conhecimento total das coisas e da dominação total do "eu" e da natureza, o que frequentemente vem disfarçada da ideia simples, universal e incontornável de um bem absoluto. Foi a partir dessa ideia que a ideologia nazista identificou um mal igualmente absoluto como seu oposto. O mal extremo e inimaginável que se materializa na Shoah, na tentativa e na forma de exterminação dos judeus e outros grupos, é íntimo da ideia da possibilidade de um bem absoluto: 


\section{1}

À chaque rue, ses souvenirs, ses hurlements, ses cris, ses sanglots. Ces souvenirs ne font pas souffrir Rabier. Ils sont les jardiniers de ce jardin-là, Paris, de ces rues qu'ils adorent, maintenant exemptes de juifs. II ne se souvient que de bonnes actions, il n'a aucun souvenir d'avoir été brutal. (DURAS, 1985, p. 117; grifos nossos)

Esse bem absoluto se oporia a um "mal" que sempre se vinculou não ao conhecimento total que tende ao controle, um modelo rígido e seguro, mas, pelo contrário, ao indistinto e ao desconhecido, àquilo que permanece incognoscível na natureza e nas próprias entranhas do humano, e que nunca se revela por completo, o que é metaforicamente representado pelos dejetos de Robert L.:

Attendre fut un long travail en face l'inconnu, c'était cela la douleur. Mais à présent, pour l'instant, l'inconnu n'a pas disparu, persistant sous forme de merde, matière informe au lieu d'images [...]. Dachau est encore en lui, et on ne peut pas savoir de quoi il s'agit. [...] Dans le corps de Robert L. une guerre contre l'absolu a eu lieu. La vie a vaincu sans qu'on sache comment. II y avait eu deux événements incompréhensibles, communs pourtant par leur sens: les camps et le ventre. (BOURDIL, 1987, p. 235-236 ; grifos nossos)

O retrato obsceno e repugnante daquilo que não estaria destinado ao mundo das aparências consiste em uma crítica tanto à ultrapassagem de determinados limites do conhecimento como ao controle do humano e da natureza, o que acaba por gerar algo muito próximo do retrato do mal extremo. Loignon (2003, p. 270) aponta que a descrição da merda de Robert L. abole as fronteiras entre o humano e o inumano, entre o reino animal e o vegetal, como assinala a comparação de seu odor com o de húmus vegetal ou folhas mortas. Duras assinala que a experiência-limite à qual é submetido Robert L. tem como natureza a ultrapassagem do limite entre o sagrado e o profano, representada pelos dejetos de Robert L., uma vez que "ce qui suscite la fascination pourrait être aussi bien objet de dégout, puisqu'il est question, pendant dix-sept jours de fièvre de Robert, de la merde qui s'échappe de son corps" (LOIGNON, 2003, p. 270). Agamben (2007, p. 75) também caracteriza as fezes como símbolo de uma separação, de algo que não pode ser dado ao uso comum: "a separação dá-se também e sobretudo na esfera do corpo, como repressão e separação de determinadas funções fisiológicas. Uma delas é a defecação, que, em nossa sociedade, é isolada e escondida através de uma série de dispositivos e proibições". E aqui essa separação é abolida, o ato de defecação está descrito, bem como os dejetos.

O excremento disforme acaba ocupando lugar central no texto, assumindo a posição última de metáfora daquilo com que a literatura se depara, o sofrimento e o horror dos deportados, que carece de definição e de nome, escapando às palavras. É esse elemento que a escritura de Duras se propõe a abordar e descrever. O texto "La douleur", ao retratar aquilo que é obsceno, as vísceras e os dejetos, torna-se uma espécie de "déchet de la littérature: ce qui est à la frontière du pur et de l'impur, su sacré et du profane" (LOIGNON, 2003, p. 271), ao que acrescentamos: do ético e do não ético. A obra La Douleur busca retratar o sofrimento e o sentido dos acontecimentos, ao mesmo tempo que procura estabelecer os limites da compreensão e da representação.

No entanto, como essa linha é tênue e a princípio invisível, a escritora acaba por vezes ultrapassando-a para compreender quais os limites éticos de sua escritura. Em um primeiro momento, 


\section{1}

a escritura da dor encontrou seu caminho pela exposição nua e crua do sofrimento por meio do corpo, como algo que escapa ao controle: "Elle est par terre, tombée. Quelque chose a crevé avec les mots disant qu'il était vivant il y a deux jours. Elle laisse faire. Ça crève, ça sort par la bouche, par le nez, par les yeux. Il faut que ça sorte" (DURAS, 1985, p. 51).

Assim, o que buscamos compreender é justamente como a obra La Douleur busca os limites entre o inominável e, portanto, insondável, e aquilo que pode ser de alguma forma apreendido. É evidente, como expressa Imre Kertész (2003, p. 44-45) em seu romance Kaddish pour l'enfant qui ne naîtra pas, que a afirmação "Auschwitz ne s'explique pas" é um contrassenso, uma vez que ela mesma já busca conferir algum sentido ao evento. No fim das contas, em alguma medida, a experiência de Duras "était, vois-tu, racontable" (DURAS, 1972, p. 110).

\section{Referências Bibliográficas}

AGAMBEN, G. Profanações. São Paulo: Boitempo, 2007.

AGOSTINHO. A doutrina cristã: manual de exegese e formação cristã. São Paulo: Paulus, 2002.

ANTELME, R. L'Espèce humaine. Paris: Gallimard, 1957.

ARENDT, H. "Compreensão e política: as dificuldades da compreensão". In: Compreender: formação, exílio e totalitarismo (ensaios) 1930-54. São Paulo: Companhia das Letras, 2008. Responsabilidade e julgamento. São Paulo: Companhia das Letras, 2004.

A vida do espírito: o pensar, o querer, o julgar. Rio de Janeiro: Relume Dumará/ UFRJ, 1992.

BAJOMÉE, D. "D'une phénoménologie de la représentation à une ontologie de la douleur". In: Duras ou la douleur. Bruxelles: De Boeck-Wesmael, 1989.

BERWANGER DA SILVA, M. L. "Marguerite Duras et l'expérience contemporaine". In: et al. Olhares sobre Marguerite Duras. São Paulo: Publisher Brasil, 2014.

BESSIĖRE, J. "Marguerite Duras dans les années 1970 et 1980. Repetitions de l'oeuvre, figures de l'incarnation: de la douleur au depassement du negatif." In.: Marguerite Duras. São Paulo: Publisher Brasil, 2014. p. 16-25. et al. Olhares sobre

BLOT-LABARRÈRE, C. Marguerite Duras. Paris: Éditions du Seuil, 1992.

BOGAERT, S. "La Douleur: Notice" . In: DURAS, M. CEuvres complètes. v. 4. Paris: Gallimard, 2014.

BORNAND, M. Témoignage et fiction: les récits de rescapés dans la littérature de langue française, 1945-2000. [S. I.]: Librairie Droz, 2004.

BOURDIL, P.-Y. Les miroirs du moi: Les Héros et les Fous. Paris: L'école, 1987.

CROWLEY, M. "A.-M. S., ou la Politique Cryptée de Duras". La Revue des Lettres Modernes, [S. I.] , v. 4 , p. 3-113, 2010.

DE CHALONGE, F. "La Douleur, le 'journal intemporel' de Marguerite Duras". In: HERMETET, A.R.; PAUL, J.-M. (Eds.). Écritures autobiographiques: Entre confession et dissimulation. Rennes: Presses Universitaires de Rennes, 2010.

DERRIDA, J. A Farmácia de Platão. Tradução de Rogerio da Costa. São Paulo: lluminuras, 2005. "Pardonner: l'impardonnable et l'imprescriptible". In: Jacques Derrida: Cahier de L'Herne. Paris: Éditions de l'Herne, 2004a. 


\section{1}

"Poétique et politique du témoignage". In: Jacques Derrida: Cahier de

l'Herne. Paris: Éditions de l'Herne, 2004b.

Témoignage (3). $1^{\text {er }}$ dec. 1993. Fac-símile de manuscrito. (Fond Jacques Derrida, DRR 178). Disponível em IMEC, Caen, França.

Témoigner (4). 9 déc. 1992. Fac-símile de manuscrito. (Fond Jacques Derrida, DRR 178). Disponível em IMEC, Caen, França.

; ROUDINESCO, E. De que amanhã: diálogo. Rio de Janeiro: Jorge Zahar, 2004.

DURAS, M. "Les yeux verts". In: CEuvres complètes. v. 3. Paris: Gallimard, 2014.

; GAUTHIER, X. "Les Parleuses". In: . CEuvres complètes. v. 3. Paris: Gallimard, 2014.

Cahiers de la guerre et autres textes. Édition établie par Sophie Bogaert et Olivier Corpet. Paris: P.O.L/Imec, 2006.

. Écrire. Paris: Éditions Gallimard, 1993.

"J'ai toujours désespérément filmé". Cahiers du Cinema, Paris, n. 426, déc. 1989 (Entrevista concedida a NOGUEZ, D.). La Douleur. Paris: P.O.L, 1985.

Hiroshima mon amour. Paris: Gallimard, 1972.

FERNANDES, M.-P. Travailler avec Duras: La musica deuxième. Paris: Gallimard, 1986.

GRÉSILLON, A. Eléments de critique génétique: Lire les manuscrits modernes. Paris: P. U. France, 1994.

HEIDEGGER, M. Parmênides. Petrópolis: Vozes, 2008.

HOMERO. "Canto XXIII". In: Odisseia. São Paulo: Cosac Naify, 2014.

HOUAISS, A. Minidicionário Houaiss da Língua Portuguesa. Rio de Janeiro: Objetiva, 2003.

KEHL, M. R. "O sexo, a morte, a mãe e o mal". In: NESTROVSKI A.; SELIGMANN-SILVA, M. (Orgs.) Catástrofe e representação: ensaios. São Paulo: Escuta, 2000.

KERTÉSZ, I. Kaddish pour l'enfant qui ne naîtra pas. Traduit du hongrois par Nathalia Zarenba -Huzsvai et Charles Zaremba. Arles: Babel, 2003.

LAMY, S.; ROY, A. (Eds.). Marguerite Duras à Montreal. Québec: Ed. Spirale, 1981.

LEBRUN, G. "Sombra e luz em Platão". In: NOVAES, A. (org.) O Olhar. São Paulo: Companhia das Letras, 1988.

LEVI, P. Os afogados e os sobreviventes: os delitos, os castigos, as penas, as impunidades. Rio de Janeiro: Paz e Terra, 2016.

LOIGNON, S. "Faire front: La Douleur de Marguerite Duras". In: MARTINIERE, N; MENAHEZE, S. (Eds.). Écrire la frontière. Limoges: Pulim, 2003.

PERRONE-MOISÉS, L. "A imagem absoluta”. In: Duras, M. O amante. São Paulo: COSACNAIFY, 2013.

. "O perdão e os crimes contra a humanidade: um diálogo entre Hannah Arendt e Jacques Derrida". In: Direito Internacional Penal: Imunidades e Anistias. São Paulo: Manole, 2012.

Flores da escrivaninha: ensaios. São Paulo: Companhia das Letras, 1990.

RICOEUR, P. Temps et récit: Le temps raconté. v. 3. Paris: Seuil, 1991. 


\section{1}

RIVETTE, J. De l'abjection. Cahiers du Cinema, [S. L.], n. 120, p. 54-55, juin 1961. Disponível em < https://www.univ-conventionnelle.com/Le-travelling-de-Kapo-De-l-abjection--texte-integral_a200.html>. Acesso em 30 nov. 2018.

ROBERT MORAES, E. "A memória da fera”. In: NESTROVSKI, A.; SELIGMANN-SILVA, M. (Orgs.). Catástrofe e representação: ensaios. São Paulo: Escuta, 2000.

SELIGMANN-SILVA, M. (Org.). História, memória, literatura: O testemunho na era das catástrofes. Campinas: Editora UNICAMP, 2003.

"A história como trauma". In: NESTROVSKI A.; SELIGMANN-SILVA, M. (Orgs.) Catástrofe e representação: ensaios. São Paulo: Escuta, 2000.

ZAMORA, J. A. "Tiempo, memoria e interrupción revolucionária: sobre la actualidad de W. Benjamin". In: ASSY, B. et al (Coord.) Direitos humanos: justiça, verdade e memória. Rio de Janeiro: Ed. Lumen Juris, 2012.

Recebido em: 30/04/2018 Aceito em: 12/09/2018

Referência eletrônica: MASCARO, Laura Degaspare Monte. A ética na representação do horror em La douleur, de Marguerite Duras. Criação \& Crítica, n. 21, p.16-36, nov. 2018. Disponível em: <http://revistas.usp.br/criacaoecritica>. Acesso em: dd mmm. aaaa. 